The management of nontuberculous mycobacterial cervicofacial lymphadenitis - a view beyond surgery

Petra Zimmermann ${ }^{1,2,3}$, MD, PhD, Nicole Ritz ${ }^{2,4,5}$, MD, PhD, Nigel Curtis ${ }^{2,3,6}$ FRCPCH, PhD, Marc Tebruegge ${ }^{2,7,8}, \mathrm{MD}, \mathrm{PhD}$

\title{
Affiliations:
}

${ }^{1}$ Department of Paediatrics, Fribourg Hospital HFR and Faculty of Science and Medicine, University of Fribourg, Switzerland

${ }^{2}$ Department of Paediatrics, The University of Melbourne, Parkville, Australia

${ }^{3}$ Infectious Diseases Research Group, Murdoch Children’s Research Institute, Parkville, Australia

${ }^{4}$ University of Basel Children's Hospital, Infectious Diseases Unit Basel, Switzerland

${ }^{5}$ Mycobacterial Research Group, Department of Clinical Research, University of Basel, Basel, Switzerland

${ }^{6}$ Infectious Diseases Unit, The Royal Children’s Hospital Melbourne, Parkville, Australia

${ }^{7}$ Department of Paediatric Infectious Diseases \& Immunology, Evelina London Children’s Hospital, Guy’s and St. Thomas’ NHS Foundation Trust, London, UK

${ }^{8}$ Department of Infection, Immunity \& Inflammation, UCL Great Ormond Street Institute of Child Health, University College London, London, UK

Running title: Nontuberculous mycobacterial lymphadenitis

Address correspondence to: Dr Petra Zimmermann, Faculty of Science and Medicine, University of Fribourg, Route des Arsenaux 41, 1700 Fribourg, Switzerland, Tel: +41 26306 0000, petra.zimmermann@unifr.ch

\section{Financial disclosure}

None of the authors received any funding.

This is the author manuscript accepted for publication and has undergone full peer review but has not been through the copyediting, typesetting, pagination and proofreading process, which may lead to differences between this version and the Version of Record. Please cite this article as doi: 10.1002/lary.28608

This article is protected by copyright. All rights reserved. 


\section{Conflict of interest}

The authors declare no conflict of interest.

This article is protected by copyright. All rights reserved. 
We read with interest the article by Harb et al. suggesting surgery should be offered to all children with cervicofacial nontuberculous mycobacterial (NTM) lymphadenitis. ${ }^{1}$ This conclusion is based on only four cited studies. As summarised in our recent meta-analysis, many other studies have investigated the three main management options - complete excision, anti-mycobacterial antibiotics and no intervention. ${ }^{2}$

Although complete excision had the highest cure rate in our meta-analysis, ${ }^{2}$ this is not invariably the best option as suggested by the authors. Management decisions regarding NTM lymphadenitis require an interdisciplinary, individualised approach considering several factors, including disease stage (excision is more likely to be successful in early stages), local surgical expertise, proximity of the lymph node to the facial nerve (complete excision is associated with $10 \%$ risk of facial nerve palsy, permanent in $2 \%$ ), and parental attitude to an invasive procedure compared with prolonged time to resolution with conservative options., 3

As evidence for 'no intervention', the authors summarise results from only two studies, both of which showed a $100 \%$ cure rate. ${ }^{4,5}$ However, there are several others, ${ }^{2}$ including a recent study from Finland, that have reported lower rates. ${ }^{6}$ Importantly, 30\% of asymptomatic children respond to Mycobacterium avium sensitin skin testing (the predominant pathogen in NTM lymphadenitis), ${ }^{7}$ suggesting subclinical and mild disease that is self-limiting is not uncommon.

This article is protected by copyright. All rights reserved. 
Regarding anti-mycobacterial antibiotics, Harb et al. mention only one randomised controlled trial that had substantial flaws, ${ }^{5}$ as detailed elsewhere. ${ }^{8}$ Although, in our meta-analysis the adjusted mean cure rate with anti-mycobacterial treatment was $73 \%$, the risk of bias is substantial as children with more advanced disease are more likely to receive antimycobacterial antibiotics. Furthermore, there was considerable heterogeneity in antibiotic choice and treatment duration across different studies. ${ }^{2}$ In our meta-analysis, adverse events were reported in $68 \%$ of children who received anti-mycobacterial treatment, but these were almost universally mild and transient, resulting in management changes in only $3 \%{ }^{2}$ Although the authors state that non-surgical options leave patients prone to fistula formation, ${ }^{1}$ in our meta-analysis only $4 \%$ of the children treated with anti-mycobacterial antibiotics developed a fistula. ${ }^{2}$

In summary, the existing evidence to guide the management of NTM lymphadenitis is limited. No randomised controlled trial has compared the three main options. Until such data become available, treatment decisions should be individualised taking into account the abovementioned factors. Importantly, while complete excision may have the highest cure rate, it also carries the highest risk of serious adverse events. 


\section{References}

1. Harb JL, Pascal E, Compton RA, Scott AR. What is the optimal management of pediatric nontuberculous mycobacterial cervicofacial lymphadenitis? The Laryngoscope. 2019.

2. Zimmermann P, Tebruegge M, Curtis N, Ritz N. The management of non-tuberculous cervicofacial lymphadenitis in children: A systematic review and meta-analysis. $J$ Infect. 2015;71(1):9-18.

3. Zimmermann P, Tebruegge M, Curtis N, Ritz N. A personalised approach is needed for the management of non-tuberculous mycobacterial cervicofacial lymphadenitis. $J$ Infect. 2016;73(4):391-392.

4. Zeharia A, Eidlitz-Markus T, Haimi-Cohen Y, Samra Z, Kaufman L, Amir J. Management of nontuberculous mycobacteria-induced cervical lymphadenitis with observation alone. Pediatr Infect Dis J. 2008;27(10):920-922.

5. Lindeboom JA. Conservative wait-and-see therapy versus antibiotic treatment for nontuberculous mycobacterial cervicofacial lymphadenitis in children. Clin Infect Dis. 2011;52(2):180-184.

6. Lyly A, Kontturi A, Salo E, Nieminen T, Nokso-Koivisto J. Childhood nontuberculous mycobacterial lymphadenitis-observation alone is a good alternative to surgery. International journal of pediatric otorhinolaryngology. 2019;129:109778.

7. Larsson LO, Bentzon MW, Lind A, Magnusson M, Sandegard G, Skoogh BE, et al. Sensitivity to sensitins and tuberculin in Swedish children. Part 5: A study of school children in an inland rural area. Tubercle and lung disease. 1993;74(6):371-376.

8. Zimmermann P, Curtis N, Tebruegge M. Nontuberculous mycobacterial disease in childhood - update on diagnostic approaches and treatment. J Infect. 2017;74 Suppl 1:S136-s142.

This article is protected by copyright. All rights reserved. 


\section{University Library}

\section{- M M I N E R VA A gateway to Melbourne's research publications}

Minerva Access is the Institutional Repository of The University of Melbourne

Author/s:

Zimmermann, P;Ritz, N;Curtis, N;Tebruegge, M

Title:

In Reference to The Management of Nontuberculous Mycobacterial Cervicofacial Lymphadenitis: A View Beyond Surgery

Date:

2020-03-10

Citation:

Zimmermann, P., Ritz, N., Curtis, N. \& Tebruegge, M. (2020). In Reference to The Management of Nontuberculous Mycobacterial Cervicofacial Lymphadenitis: A View Beyond Surgery. LARYNGOSCOPE, 130 (12), pp.E945-E946. https://doi.org/10.1002/lary.28608.

Persistent Link:

http://hdl.handle.net/11343/275525 